\title{
SISTEM PENGANGGARAN PELAKSANAAN PENDIDIKAN MADRASAH IBTIDAIYAH SWASTA DI KECAMATAN GEDEG KABUPATEN MOJOKERTO
}

\author{
Imam Baidlowi \\ Universitas Pesantren Tinggi Darul 'Ulum Jombang \\ Email: imambaidlowiku@gmail.com
}

\begin{abstract}
Abstrak
Fokus penelitian ini adalah pada sistem penganggaran pelaksanan pendidikan di Madrasah Ibtidaiyah Swasta yang ada pada Madrasah Ibtidaiyah "Irsyadudul Ummah" Desa Balongsari Kecamatan Gedeg. Permasalahan penelitian ini adalah mengidentifikasikan adanya sistem penganggaran pelaksanaan pendidikan di Madrasah Ibtidaiyah Swasta, mengngat adanya ketentuan dari Pemerintah bahwa dilembaga pendidikan tingkat dasar tidak menarik Sumbangan Pembinaan Pendidikan (SPP).

Tujuan penelitian ini adalah pertama, untuk mengetahui apakah terjadi perubahan Sistem penganggaran Madrasah Ibtidaiyah Swasta "Irsyadul Ummah"setelah Keputusan Pementah Republik Indonesia adanya ketetapan tentang biaya pelaksanakan pendidikan dasar di tanggung oleh pemerintah. Kedua untuk mengetahui apakah terjadi perubahan anggaran pelaksanaan pendidikan di Madrasah Ibtidaiyah Ibtidaiyah "Irsyadul Ummah" Kabupaten Mojokerto.. Ketiga untuk mengetahui apakah terjadi perubahan Kualiatas lulusan dari para siswa/siswi Madrasah Ibitidaiyah "irsyadul Ummah"

Hasil peneltian ini menunjukkan bahwa sitem penganggaran sekolah telah berubah teriring dengan adanya Bantuan Operasinal Sekolah (BOS) dari Pemerintah. Akibatnya, banyak terjadi perubahan bagi penganggaran yang diikitu oleh tata perubahan pertanggung jawaban anggaran Madrasah. Kalau sebelum adanya BOS dan, semua anggaran pembiayaan pendidikan Madrasah Ibtidaiyah "Irsyadul Ummah" berasal dari Sumbangan Pelaksanaan Pendidikan (SPP) dan sumbangan lain serta dari Pengurus Madrasah(Yayasan), yang pertanggung jawabanya tidak begitu ketat. Dengan adanya BOS Tunjungan Profesi Pendidik (TPP) maka harus meningkatkan sistem kinerja yang profesional agar Madrasah dan para guru mendapatkan BOS dan TPP.
\end{abstract}

Kata Kunci: Sumbangan Pembinaan Pendidikan, Bantuan Operasinal Sekolah, Kualiatas lulusan

\begin{abstract}
The focus of this research is on education budgeting system implementation in Private Madrasah Ibtidaiyah which is in Madrasah Ibtidaiyah "Irsyaditle Ummah" Balongsari Village Gedeg Subdistrict. The problem of this research is to identify a system of budgeting for the implementation of education in Private Madrasah Ibtidaiyah, remembering the provision from the Government that the institute of elementary education does not attract Education Contribution Contribution.

The purpose of this research is first, to find out whether there is a change of system of budgeting of Private Madrasah Ibtidaiyah "Irsyadul Ummah" after Decision of Pementah Republic of Indonesia there is a provision about the cost of implementing basic education in responsibility by government. Secondly to find out whether there is a change of education budget implementation in Madrasah Ibtidaiyah Ibtidaiyah "Irsyadul Ummah" Mojokerto regency.. Thirdly to know whether there is a change of graduates from graduates of Madrasah Ibitidaiyah students "irsyadul Ummah"

The results of this study indicate that the school budgeting system has changed along with School Operational Assistance (BOS) from the Government. As a result, there are many changes to the budgeting that is followed by changes in the accountability of the Madrasah budget. If before the BOS and, all the educational budget of Madrasah Ibtidaiyah education "Irsyadul Ummah" comes from the Contribution of Education Implementation (SPP) and other donations and from the Management of Madrasah (Foundation), whose responsibility is not so tight. With the BOS Tunjungan Profession Educator (TPP) then must improve the professional performance system for Madrasahs and teachers get BOS and TPP.
\end{abstract}

Keyword: Contribution of Educational Development, School Operational Assistance, Quality of graduates

\section{PENDAHULUAN}

Madrasah Ibtidaiyah"Irsyadul Ummah" Desa Balong sari Kec. Gedeg Kab. Mojoketo adalah lembaga pendidikan formal keagamaan Islam jenjang sekolah dasar yang diselenggarakan Yayasan Pendidikan Islam dan Sosial "Irsyadul Ummah" yang berhalauan Ahlusunawal jamaah, dalam wadah Lembaga Pendidikan Ma'arif 
Nahdlotul Ulama'

Madrasah ini dalam pembinaan operasonalnya dibawah pembinaan Kementerian Agama Republik Indonesia, yang scara langsung ditantangai oleh Kantor Kementerian Agama Republik Indosia Kabupaten Mojokerto

Penyelenggara Lembaga Madrasah Ibtidaiyah Irsyadul Ummah adalah Yayasan Pendidikan,Sosial dan Pondok Pesantren dalam Pembinaan Lembaga Pendidikan Ma'arif Nahdlotun Ulama' Kabupate Mojoketo,

Untuk memperjelas dan mempertajam fokus kajian penelitian ini, maka fokus penelitian disusun sebagai berikut: (1) Bagaimana sistem anggaran dan penganggran pelaksanaan pendidikan di Madrasah mengingat ada aturan dari Pemerintah bahwa lembaga pendidikan dasar tidak boleh narik Sumbangan Pembinaan Pendidikan (SPP)?; (2) Bagaimana cara memperoleh Pendapatan lain selain dari Bantuan Opersional Sekolah (BOS)?; (3) Bagaimana sistem penggajiannya Guru, Kepala Sekolah dan Petugas kependidikan?; Bagaaimana sistem pengadaan,perbaiakan dan perawatan sarana dan prasarana Madrasah?.

Penelitian yang lakukan ini ini bertujuan untuk: (1) Mengetahui Sistem anggaran dan penganggaran pelaksanaan pendidikan di Madrasa Ibtidaiyah; (2) Mengetahui Sumber Pendapatan dari Madrasah Ibtidaiyah selain dari BOS; (3) Mengetahui sistem penggajiannya Guru, Kepala Sekolah dan Petugas kependidikan Madrasah Ibtidaiyah Ibtidaiyah; (4) Mengetahui sistem pengadaan,perbaiakan dan perawatan sarana dan prasarana Madrasah

\section{METODE}

Secara umum penelitian ini untuk mendeskripsikan dan menganalisa Sistem Penganggaran Pelaksanaan Pendidikan di Madrasah Ibtidaiyah "Irsyadul Ummah", Sumber dana pendidikan ,dan kualitas pendidikan yang dihasilkan. Oleh karena itu, dalam penelitian ini peneliti menggunakan pendekatan penelitian kualitatif.

Pendapat Moleong (2008), Rancangan penelitian disusun melalui tiga tahap, di antaranya adalah: (1) tahap pra lapangan, (2) tahap kegiatan lapangan, dan (3) analisis dan uji keabsahan.

1. Tahap Pra-lapangan

2. Tahap Kegiatan Lapangan

3. Analisis dan Uji keabsahan

Dalam memperoleh sumber data

dikelompokan menjadi dua, yaitu data primer dan data sekunder. Data primer meliputi hasil wawancara dengan para informan dan hasil pengamatan lapangan yang berupa catatan lapangan, rekaman suara wawancara

a. Informan

b. Dokumen

c. Pengumpulan data: wawancara, pengamatan, studi dokumen.

Data yang telah dipeoleh dianalisis secara kritis dan logis sesuai dengan kondisi sosial setempat. Interpretasi secara sistematis sesuai dengan penelitian kuantitatif. Data yang diperoleh di lapangan dalam bentuk narasi dan argumen kuantitatif akan dirinci dengan baik agar dapat membuat sehingga dapat ditarik suatu kesimpulan dengan tepat.

Keabsaan data pada penelitian ini menggunakan empat standar kriteria yang diangggap mampu menjamin keabsahan hasil penelitian kualitatif,

Tempat atau lokasi penelitian adalah di Madrasah Ibtidaiyah "Irsyadul Ummah" Desa Balongsari Kecamatan Gedeg Kabupaten Mojokerto. Dipilih lokasi ini karena di Madrasah Tersebut disamping Madrasah tertua di kecamatan Gedeg, juga sering jadi rujukan bagi madrasah di sekitarnya dalam pengelolahan keuangan Madrasah

Waktu penelitian adalah pada akhir tahun ajaran 2015/2016 sampai dengan awal tahun ajaran 2016/2017, tepatnya di bulan Juni,Juli dan Agustus 2016. Dipilih pada waktu tersebut, karena di setiap akhir dan awal tahun ajaran ditutupnya anggaran Madrasah dan dimulainya anggaran yang baru untuk satu tahun berikutnya.

\section{HASIL DAN PEMBAHASAN}

Pada bab ini disajikan tentang hasil penelitian lapangan yang merupakan kondisi obyektif yang ditemukan di lapangan dan merupakan gambaran sistem penganggaran di Madrasah selama satu tahun yang sudah terjadi dan satu tahun yang akan datang dan merupakan kondisi keuangan yang sudah terjadi dan kondisi keuangan yang akan terjadi.Gambaran Sistem Penganggaran Pelaksanaan Pendidikan di Madrsah Ibtidaiyah "Irsyadul Ummah"

Sistem Penggangaran Pelaksnakaan Pendidikan di Madrasah Ibtidaiyah "Irsyadul Ummah" yang temuat dalam Anggaran Pendapatan dan Belanja Madrasah sepenuhnya dibuat oleh guru dan kepala madrasah komite sekoalah dan Yayasan 
tidak dilibatkan, jadi pada kesempulannya Anggaran Pendapatan dan Belanja Madrasah dibuat sendiri antar guru, karyawan dan kepala madrasah dan dilaksanakan sendiri oleh pihak pengeleloh sekolah bersama stafnya.

Jadi sistem pengelolaan anggaran sepenuhnya dilaksanak oleh pihak pengelolah madrasah, yayasan dan komitesekolah melihat dan mengawasi apakah pengeloaan keuangan (Penganggaran) madrasah itu dilaksanakan dengan trasparan atau tidak,mengingat tujuan penyelenggaran dengan mewaqafkan madrasah itu dulu murni untuk kepentingan agama dan ummat.

Gambaran Anggaran yang keluarakan Madrasah Ibtidaiyah "Irsyadul Ummah" Pertahun. Anggaran Madrsah Ibtidaiyah " Irsyadul Ummah" Th Ajaran 2015/2016.

\begin{tabular}{|l|l|r|}
\hline No & Uraian & Jumlah/Rp \\
\hline 1 & $\begin{array}{l}\text { Pembilian Alat Tulis } \\
\text { Kantor. }\end{array}$ & $2.114 .600,-$ \\
\hline 2 & Kelengkapan PBM di kelas & $2.113 .400,-$ \\
\hline 3 & Rekening Listrik & $2.100 .000,-$ \\
\hline 4 & Rekening tilpun dan spidi & $500.000,-$ \\
\hline 5 & $\begin{array}{l}\text { Perawatan alat elekt. \& } \\
\text { puterputer }\end{array}$ & $\begin{array}{l}\text { Perawatan fasilitas non } \\
\text { elektronik }\end{array}$ \\
\hline 6 & Pelaksanan rapat & 900.000,- \\
\hline 7 & $\begin{array}{l}\text { Ulangan/ujian/ pembagian } \\
\text { Raport }\end{array}$ & $\begin{array}{l}\text { Gaji/tunjagan karyawan dan } \\
\text { guru }\end{array}$ \\
\hline 9 & $\begin{array}{l}\text { Pengeluaran yang tak } \\
\text { terduga/taktis }\end{array}$ & $2.107 .000,-$ \\
\hline
\end{tabular}

\section{Dan dana bantuan dari BOS sebanyak} Rp.74.240.000,-

Penyebab Perubahan Penganggaran Madrasah Ibtidaiyah "Irsyadul Ummah"

Dengan adanya bantuan dari pemerintah yang berupah Bantuan Operasinal Sekolah (BOS) dan Tunjangan Profesi Pendidik maka berpengaruh langsung pada Perubahan sistem Penggagaran Madrasah Ibtidaiyah "Irsyadul Ummah" membawah dampak kepada perubahan kinerja para guru dan karyawan Madrasah sehingga hal bisa mempengarui kwalitas pendidikan di Madrasah Ibtidaiyah "Irsyadudul Ummah"

\section{Hasil Lulusan Madrasah Ibtidaiyah "Irsyadul Ummah"}

Memperhatikan hasil lulusan Madrasah Ibtidaiya "Irsyadul Ummah" berdasarkan hasil wawancara peneliti dengan responden, sejak keuangan madrasah lancar apalagi dapat bantuan dari pemerintah pusat yang berupa BOS dan TPP maka pendidikan selalu meningkat dari tahun ke tahun.

Kondisi semacam ini diperkuat dengan kondisi guru cukup dan dapat penghasilan yang cukup dari mengajar di Madrasah.

\section{Implementasi Hasil Penganggaran Pelaksanaan Pendidikan Madrasah Ibtidaiyah.}

Dengan Sistem Penganggaran Madrasah cukup dan mumpuni bagi pengelolahan madrasah diharapkan mempu mendukung pelaksanaan madrasah,tetapi juga apabila penganggaran Madrasah kurang mencukupi akan mempengarui pelaksanaan dengan baik.

Pengangaran di Madrasah Ibtidaiyah memang tidak sepenuhnya mencukupi semua program pelaksanaan pendidikan Madrasah secara mumpuni namun dengan adanya BOS dan TPP secara otomatis menbantu kebutuhan angaran dalam kegiatan pembelajaran dan kesejahteraan guru.

\section{Perubahan Penganggaran Madrsah}

\section{Hasil Pelaksanaan pendidikan di Madrasah}

Dengan memperhatikan kondisi yang ada bahwa pemerintah melarang madrasah manarik SPP ke marid karena sudah di bantu dengan BOS dan TPP,namun dengan adanya kemajuan teknologi pembelajaran secara otomatif harus didukung anggaran yang cukup maka bantuan dari berbagi pihak perlu untuk dikembangkan dengan tidak melanggar aturan yang ada.

\section{PENUTUP}

Dengan adanya bantuan dari Pemerintah yang berupa Bantuan Operasinal Sekolah (BOS) dan Tunjangan Pofesi Pendidik (TPP) menjadikan sistem penganggaran di Marasah Ibtidaiyah " Irsyadul Ummah",semakin mumpuni.

Untuk memenuhi kebutuhan pengembangan pelaksanaan pendidikan Madrasah yang lebih optimal,perlu adanya dukungan dari yayasan dan masyarakat serta pihak pemangku kepentingan.

Bila mungkin Pemerintah Daerah seharusnya membuat PERDA tentang bantuan pelaksanaan pendidikan dasar,karena BOS dan TPP adalah bantuan dari pemerintahan pusat yang bersumber dari APBN,sebab PEMDA punya tanggung pada pembinaan pendidikan.

Dengan beban biaya pelaksanaan pendikan siiring dengan kemajuan ilmu pengetahuan dan teknologi,yang harus dibarengi dengan peningkatan proses pendidikan,maka para pemengku kepentingan pada Madrasah mencari langka yang normatif untuk menaikan anggara pendapatan dan belanja madrasah

\section{DAFTAR PUSTAKA}

Usman Husaini, 2014, Manajemen Teori, Praktik,Riset Pendidikan, PT Bumi Aksara, 
Jakarta, 13220

Mulyasa, 2012, Manajemen \& Kepemimpinan Kepala Sekolah, PT Bumi Aksara, Jakarta.

K. Hoy Wayne dan G. Miskel Cecil, Cecil, 2014, Administrasi Pendidikan, Penerbit Pustaka Pelajar, Yogyakarta,55167

Moeleong, Lexy, J., 2008, Metodologi Penelitian Kuantitatif, PT. Remaja Rosdakarya, Bandung.

Brunette, Marielle, dkk, 2013, Hedging Strategies in Forest Management, online at http://mpra.Ub.Unimuenchen.De/5228/MPRA Paper No. 5228, posted 07. Nopember 2007.

Mariam, Yohannes, 2012, The Implication of Incorporating Environmental Costs in Utility Rate Setting, online at http://mpraub.Uni-muenchen.De/412/MPRA Paper No. 412, posted 07. Nopember 2007. 